\title{
ESTUDOS MORFO-ANATÔMICOS, BIOQUÍMICOS E FISIOLÓGICOS DURANTE A GERMINAÇÃO DE SEMENTES DE CANDEIA (Eremanthus erythropappus) (DC.) MacLeish $^{1}$
}

\author{
ANTONIO CLÁUDIO DAVIDE², CAROLINA SOUZA JAROCHINSKI E SILVA ${ }^{3}$, EDVALDO APARECIDO AMARAL DA SILVA², LÍLIAN \\ VILELA ANDRADE PINTO4 ${ }^{4}$, JOSÉ MARCIO ROCHA FARIA²
}

\begin{abstract}
RESUMO - O objetivo deste trabalho foi realizar um estudo morfo-anatômico, bioquímico e fisiológico em sementes de Eremanthus erythropappus (DC.) MacLeish (candeia) durante a germinação. As sementes possuem tegumento de coloração marrom clara e apresentam saliências. O endosperma é bastante reduzido apresentando duas a três camadas de células em torno do embrião. $\mathrm{O}$ embrião compõe a maior parte da semente. A condição mais adequada para a germinação das sementes foi fotoperíodo de $14 \mathrm{~h}$ associado à temperatura alternada de $20-30^{\circ} \mathrm{C}$. Nestas condições, o início da germinação ocorreu após $48 \mathrm{~h}$ de embebição e a germinação máxima $(96 \%)$ foi obtida no oitavo dia. As sementes absorveram água segundo um padrão trifásico, sendo a primeira fase rápida e com aumento de massa fresca da semente em $95 \%$. As primeiras modificações morfológicas no tegumento ocorreram após o primeiro dia de embebição. O surgimento de rupturas no tegumento e o crescimento visível da raiz primária coincidiram com a retomada do aumento na massa fresca da semente, marcando o início da fase III de embebição. Observou-se atividade da enzima endo- $\beta$-mananase após $12 \mathrm{~h}$ de embebição, porém, aumento nessa atividade foi observado a partir do quarto dia de embebição, coincidindo com o percentual de 50\% de germinação das sementes. Assim, conclui-se que mudanças morfo-anatômicas, bioquímicas e fisiológicas ocorreram durante a embebição e se acentuaram com a germinação das sementes e crescimento da raiz primária.
\end{abstract}

Termos de indexação: microscopia de varredura, endo- $\beta$-mananase, candeia, embebição.

\section{MORPHO-ANATOMICAL, BIOCHEMICAL AND PHYSIOLOGICAL STUDIES IN SEEDS OF Eremanthus erythropappus (DC.) MacLeish DURING GERMINATION}

\begin{abstract}
The objective of this study was to perform morpho-anatomical, biochemical and physiological studies on seeds of Eremanthus erythropappus (DC.) MacLeish during germination. The results showed that the best condition to germinate the seeds was a 14h photoperiod associated with alternating temperature $20-30^{\circ} \mathrm{C}$. Under this condition the seeds started germination at $48 \mathrm{~h}$ of imbibition and reached the maximum germination (96\%) on the eighth day of imbibition. The imbibition curve showed a three-phase pattern where the first phase had a fast increase in the fresh weight of $95 \%$. The seeds have a light brown-colored tegument and saliencies. The endosperm is extremely reduced presenting two to three cell layers surrounding the embryo. The embryo makes up most of the seed. The first morphological modifications in the tegument occurred on the first day of imbibition. The beginning of ruptures in the tegument and visible primary root growth coincided with the increase in the fresh weight of the seeds, the start of phase III of imbibition and advance in the
\end{abstract}

${ }^{1}$ Submetido em 13/09/2007. Aceito para publicação em 06/06/2008. ${ }^{2}$ Universidade Federal de Lavras, Departamento de Ciências Florestais, Laboratório de Sementes Florestais. CP 3037, 37200-000, Lavras, MG, Brasil.e-mail: acdavide@ufla.br; amaral@ufla.bre jmfaria@ufla.br.3 Estudante de Engenharia Florestal da Universidade Federal de Lavras,
Laboratório de Sementes Florestais. CP 3037, 37200-000, Lavras, MG, Brasil. e-mail: carolsjs@gmail.com. ${ }^{4}$ Escola Agrotécnica Federal de Inconfidentes - CEP 37576-000 - Inconfidentes, MG, Brasil. e-mail: lilianvap@gmail.com 
germination progress. The activity of the enzyme endo- $\beta$-mannanase was present at $12 \mathrm{~h}$ imbibition, but increase in activity was observed from the fourth day of imbibition onwards, coinciding with $50 \%$ of germination of the seeds. Thus, morpho-anatomical, physiological and biochemist changes occurred during imbibition and increased with the germination process of the seeds.

Index terms: scanning electronic microscopy, endo- $\beta$-mannanase, candeia, imbibition curve

\section{INTRODUÇÃO}

Eremanthus erythropappus (DC.) MacLeish, conhecida vulgarmente como candeia, é uma espécie arbórea do grupo ecológico das pioneiras pertencente à família Asteraceae (Oliveira-Filho, 2006), ocorrendo em áreas abertas e de pastagens nos estados do Rio de Janeiro, Bahia e Minas Gerais. Em Minas Gerais a espécie é encontrada em regiões montanhosas de solos pedregosos e de altitudes que variam de 700-1200m, especialmente na região de Ouro Preto (CETEC, 1994). No ambiente natural de ocorrência, a espécie apresenta árvores pequenas, com altura que pode atingir até $6 \mathrm{~m}$ e diâmetro de tronco em torno de 50cm (NEMAF, 2007). Os principais usos econômicos da candeia são na produção de mourões de cerca e a extração do óleo alfa-bisabolol, usado pela indústria farmacêutica e de cosméticos para a produção de pomadas, géis, loções, cicatrizantes e hidratantes (Pérez, 2001).

A unidade de dispersão da candeia é um aquênio cilíndrico, de cor escura, com aproximadamente $2 \mathrm{~mm}$ de comprimento. O embrião possui cotilédones de coloração amarela e um eixo hipocótilo-radícula curto (Chaves e Ramalho, 1996).

Inicialmente, Chaves e Ramalho (1996) mostraram que sementes de candeia têm baixa germinação devido à ocorrência de dormência ou à presença de grandes quantidades de sementes vazias no momento da dispersão. Tonetti et al. (2006) testaram estas hipóteses e demonstraram que a baixa germinação era devido à presença de grandes quantidades de sementes vazias e mal formadas. Estes estudos foram importantes para identificar a causa da baixa germinação de sementes desta espécie, tendo proporcionado o emprego de metodologias para a correta análise da qualidade física e fisiológica das mesmas. Todavia, em sementes de candeia, ainda faltam trabalhos que caracterizem morfoanatomicamente as sementes e que procurem associar essas mudanças a eventos bioquímicos e fisiológicos que ocorrem durante a embebição e germinação (emissão da raiz primária).
Para Bewley (1997), em algumas sementes a germinação ocorre devido ao enfraquecimento dos tecidos que circundam o embrião permitindo, dessa forma, o alongamento da radícula. Neste caso, o potencial de pressão $\left(\psi_{\mathrm{p}}\right)$ no embrião não é suficiente para levar à expansão das paredes celulares e crescimento do mesmo. A redução da resistência mecânica, imposta pelo endosperma, ao alongamento da radícula é controlada pela ação de enzimas como endo- $\beta$-mananase. Em sementes de café (Coffea arabica), a degradação do endosperma micropilar é devida à ação da enzima endo- $\beta$ mananase facilitando a emissão da raiz primária (Da Silva et al., 2004).

Por outro lado, em sementes de alface, que também pertence à família Asteraceae, a atividade da enzima endo- $\beta$-mananase aumenta apenas após a emissão da raiz primária (Wang et al., 2004). Neste caso, apenas o aumento no potencial de pressão das células do embrião parece ser suficiente para que ocorra a extensão das células da radícula e leve a germinação das sementes.

Assim, este trabalho teve como objetivo realizar um estudo morfo-anatômico e fisiológico nas sementes de Eremanthus erythropappus (candeia), e quantificar a atividade da enzima endo- $\beta$-mananase durante a germinação.

\section{MATERIAL E MÉTODOS}

\section{Beneficiamento das sementes}

As infrutescências de Eremanthus erythropappus (DC.) MacLeish (candeia) foram coletadas no município de Carrancas, sul de Minas Gerais, em altitudes que variaram de 890 a $1000 \mathrm{~m}$. As infrutescências foram transportadas ao Laboratório de Sementes Florestais da Universidade Federal de Lavras, onde foram secas e manualmente beneficiadas para a obtenção das sementes. Utilizou-se o soprador do tipo South Dakota, regulado na abertura 6 por 30s, para eliminação das sementes vazias (Tonetti et al., 2006). Após o beneficiamento, as sementes foram armazenadas por uma semana em sacos de papel em uma sala de secagem regulada 
a $20^{\circ} \mathrm{C}$ e $60 \%$ de umidade relativa (UR), quando se iniciaram os experimentos.

Germinação: as sementes foram previamente desinfestadas em solução de hipoclorito de sódio (1\% por 10min), em seguida lavadas em água corrente e rapidamente secadas em papel toalha, para remover o excesso de água superficial. Posteriormente, as sementes foram colocadas para germinar sobre duas folhas de papel mata borrão, embebidas em água destilada, em caixas de plástico, transparentes ("gerbox"), mantidas em B.O.D., com quatro lâmpadas fluorescentes de 20 Watts cada, regulada à temperatura alternada de $20-30^{\circ} \mathrm{C}$ com fotoperíodos de 10 e de $14 \mathrm{~h}$, sendo que o período luminoso foi aplicado junto à temperatura mais alta. Foram usadas quatro repetições de 25 sementes. A germinação das sementes foi avaliada diariamente usando-se o critério da emissão da raiz primária com pelo menos $2 \mathrm{~mm}$ de comprimento.

Curva de embebição: as sementes, em duas repetições de 0,05g, foram colocadas para embeber sobre duas folhas de papel mata borrão embebidas em água destilada, em caixas para germinação. As caixas foram mantidas em incubadora B.O.D., com quatro lâmpadas fluorescentes de 20 Watts cada, regulada na temperatura alternada de $20-30^{\circ} \mathrm{C}$ com fotoperíodo de $14 \mathrm{~h}$. A cada $6 \mathrm{~h}$ as sementes foram retiradas e pesadas em balança, com precisão de 0,0001 g, até a emissão de raiz primária.

Caracterização morfo-anatômica da semente a partir da microscopia eletrônica de varredura: as sementes foram colocadas para germinar conforme descrito acima. Diariamente, amostras de sementes foram retiradas para a obtenção de imagens por microscopia de varredura. As sementes embebidas foram imersas em nitrogênio líquido e cortes longitudinais foram realizados com o uso de um bisturi, evitando-se assim que as sementes fossem danificadas. A seguir, foram imersas em solução fixadora (Karnovisk's modificado), $\mathrm{pH} 7,2$ por um período mínimo de $24 \mathrm{~h}$, lavadas em tampão cacodilato (três vezes a cada $10 \mathrm{~min}$ ) para retirar os resíduos de glutaraldeído, pós-fixadas em tetróxido de ósmio $1 \%$ em água por $1 \mathrm{~h}$ (misturando-se volumes iguais de tetróxido de ósmio $2 \%$ em tampão cacodilato $0,1 \mathrm{M}$ ). Após este período, as amostras foram lavadas por três vezes em água destilada e, em seguida, desidratadas em gradiente de acetona $(25,50,75,90$ e $100 \%$ por três vezes). Posteriormente, o material foi levado ao aparelho de ponto crítico para completar a secagem, montados em stubs e cobertos com ouro (Alves, 2004). As imagens das sementes foram feitas em microscópio eletrônico de varredura (Leo Evo 40), no Laboratório de Microscopia Eletrônica e Análise
Ultra-Estrutural, da Universidade Federal de Lavras.

Atividade da enzima endo- $\beta$-mananase: foi quantificada durante a germinação na temperatura de $20-30^{\circ} \mathrm{C}$ e fotoperíodo de $14 \mathrm{~h}$. A cada $12 \mathrm{~h}$, amostras de 20 sementes eram retiradas e armazenadas em freezer $\left(-20^{\circ} \mathrm{C}\right)$. Para a extração da endo$\beta$-mananase, as sementes foram maceradas em $200 \mu \mathrm{L}$ de tampão Mcllvaine (0,05M ácido cítrico/0,1M Na $\mathrm{HPO}_{4}$, pH 5,0) acrescido de 0,5M NaCl. Em seguida, o macerado foi centrifugado a $4^{\circ} \mathrm{C} / 30 \mathrm{~min}$ e o sobrenadante removido e transferido para um novo microtubo. Para quantificar a atividade de endo- $\beta$-mananase, $2 \mu \mathrm{L}$ do extrato foram aplicados em furos feitos no gel $(0,75 \mathrm{~mm}$ de espessura) contendo $0,5 \%$ (p/v) de "locust bean gum” (Sigma) em tampão de Mcllvaine (pH 5,0) e 0,8\% de agarose do tipo III-A (Sigma) sobre um "gelbond film" (Pharmacia). Após a aplicação dos extratos, o gel foi incubado a $25^{\circ} \mathrm{C} / 21 \mathrm{~h}$, e então lavado com o tampão de Mcllvaine (pH 5,0)/30min, colorido com Vermelho do Congo (Sigma) $0,5 \%(\mathrm{p} / \mathrm{v}) / 30 \mathrm{~min}$, lavado em etanol $90 \% / 15 \mathrm{~min}$ e revelado em $\mathrm{NaCl} 1 \mathrm{M}$ por $5 \mathrm{~min}$. Todos os passos da revelação foram feitos sobre uma plataforma agitadora com movimentos rotatórios na horizontal. A atividade da endo$\beta$-mananase foi identificada pela ocorrência de círculos brancos no gel e calculada utilizando a média das medidas do diâmetro de cada amostra em duas direções com um paquímetro digital, em três repetições (Downie et al., 1994). Os cálculos foram feitos de acordo com Downie et al. (1994) por meio de comparação com uma curva padrão de endo$\beta$-mananase de Aspergillus niger (Megazyme, North Rocks, Sydney, Austrália).

\section{RESULTADOS E DISCUSSÃO}

\section{Germinação e curva de embebição das sementes}

A germinação das sementes iniciou-se no segundo dia de embebição apresentando $4 \%$ de germinação, independentemente do fotoperíodo usado. O percentual de emissão de raiz primária, após 4 dias de embebição a 20$30^{\circ} \mathrm{C}$ com fotoperíodo de $14 \mathrm{~h}$, foi de $47 \%$, enquanto com fotoperíodo de $10 \mathrm{~h}$ foi de $19 \%$. Com $14 \mathrm{~h}$ de fotoperíodo, a $20-30^{\circ} \mathrm{C}$, ocorreu o máximo de germinação $(96 \%)$ aos oito dias após a semeadura; com $10 \mathrm{~h}$ de fotoperíodo isto ocorreu apenas com 11 dias, ou seja, três dias depois (Figura 1). Aparentemente, estas condições se aproximam das condições naturais de ocorrência da espécie. Tonetti et al. (2004), estudando diferentes regimes de temperatura para a 
germinação de sementes de E. erythropappus, concluíram que a temperatura alternada de $20-30^{\circ} \mathrm{C}$ associada ao fotoperíodo de $10 \mathrm{~h}$ proporcionou a melhor condição de germinação. Todavia no presente trabalho, o aumento do fotoperíodo em $4 \mathrm{~h}$, ou seja, de 10 para $14 \mathrm{~h}$, foi ainda mais eficiente em promover a germinação das sementes de E. erythropappus. A alternância de temperatura também se mostrou importante para o percentual e a velocidade de germinação de outras espécies tais como Sebastiania commersoniana (Santos e Aguiar, 2005) e Solanum lycocarpum (Pinto et al., 2007). Em sementes de $S$. lycocarpum o efeito da alternância da temperatura acelera a degradação do endosperma micropilar (Pinto et al., 2007), tecido que circunda o embrião e que normalmente oferece barreira mecânica à passagem do mesmo. Segundo Copeland e McDonald (1999) é possível que temperaturas alternadas quebrem o balanço inibidor/ promotor, fazendo com que o inibidor diminua durante o ciclo de baixas temperaturas, enquanto os promotores aumentem durante o período de altas temperaturas e desta forma promovendo a germinação.

FIGURA 1. Germinação de sementes de Eremanthus erythropappus na temperatura de $20-30^{\circ} \mathrm{C}$ com $14 \mathrm{~h}(\bullet)$ e $10 \mathrm{~h}(\circ)$ de fotoperíodo.



As sementes de E. erythropappus apresentaram três fases de embebição no período de 120h (Figura 2). Durante a primeira fase verificou-se rápida embebição nas seis primeiras horas, com aumento de $80 \%$ na massa fresca das sementes que continuou crescente até atingir a fase II, em torno de $24 \mathrm{~h}$ de embebição, totalizando $95 \%$ de aumento na massa fresca. Durante a fase II as sementes permaneceram sem claro aumento na massa fresca. Em geral, a fase III iniciou a partir de 96h de embebição, que caracteriza o final do processo germinativo e início do crescimento e estabelecimento da plântula. Segundo Bewley e Black (1994), a rápida absorção de água na fase I é um processo puramente físico que ocorre independentemente da semente ser viável ou morta e dormente, a não ser que trate de dormência imposta pela impermeabilidade do tegumento.

FIGURA 2. Fases (I, II e III) do processo de embebição de sementes de Eremanthus erythropappus, na temperatura de $20-30^{\circ} \mathrm{C}$ e fotoperíodo de 14 horas . (Pontos representam a média de duas amostras com $0,05 \mathrm{~g}$ de sementes por repetição)

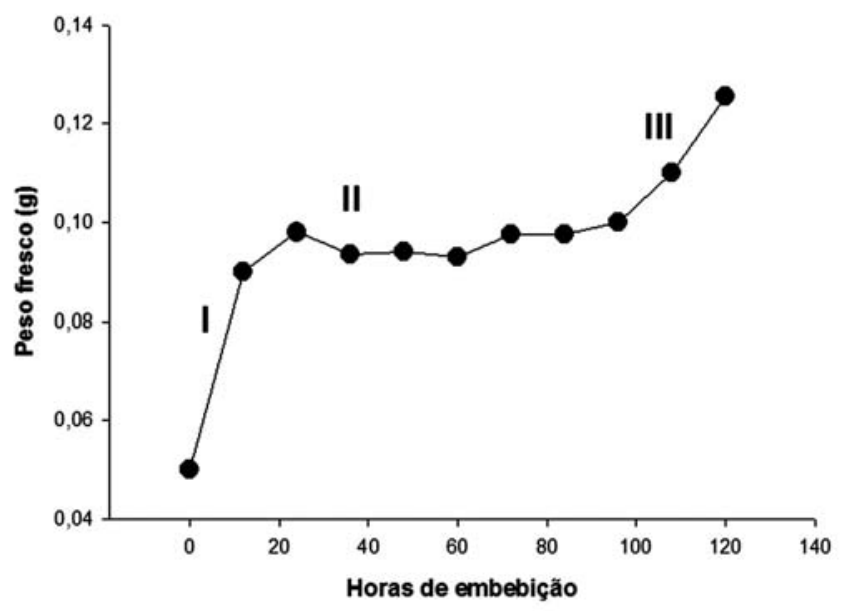

Morfo-anatomia das sementes e atividade de endo- $\beta$ mananase

A semente de candeia apresenta coloração marrom clara e no tegumento há saliências no sentido longitudinal. As características estruturais registradas antes e durante a germinação mostraram o rompimento do tegumento e o crescimento da raiz primária ao longo de cinco dias de embebição. Antes da embebição, as sementes não apresentaram rupturas no tegumento (Figura 3A). As primeiras modificações morfológicas ocorreram após o primeiro dia de embebição, sendo mais evidentes após o segundo dia (Figura 3B). A partir do terceiro dia de embebição foi possível verificar a germinação das sementes caracterizada pela emissão da raiz primária (Figuras 3C, 3D e 3E), contrastando com a Figura 3F, que mostra o embrião encaixado nas estruturas mais externas da semente (endosperma e tegumento) antes da emissão da raiz primária. O endosperma micropilar é bastante reduzido com duas a três camadas de células (Figura 3F). O embrião ocupa a maior parte da semente embebida (Figura 3F). Após a germinação e com o crescimento da raiz primária houve a formação de diversos pêlos radiculares (Figura 3E). 
FIGURA3. Germinação da semente de Eremanthus erythropappus: A) Semente seca; B) Dois dias de embebição mostrando rompimento do tegumento; C) Três dias de embebição e início da emissão da raiz primária; D) Quatro dias de embebição e continuação do crescimento da raiz primária; E) Crescimento da raiz primária e formação de pêlos radiculares (Seta indica a presença de pêlos radiculares); F) Corte longitudinal da semente com indicações do embrião (emb), endosperma micropilar (end) e tegumento (teg). Barras representam $200 \mu \mathrm{m}$ para as Figuras A-E e $100 \mu$ m para a Figura F.
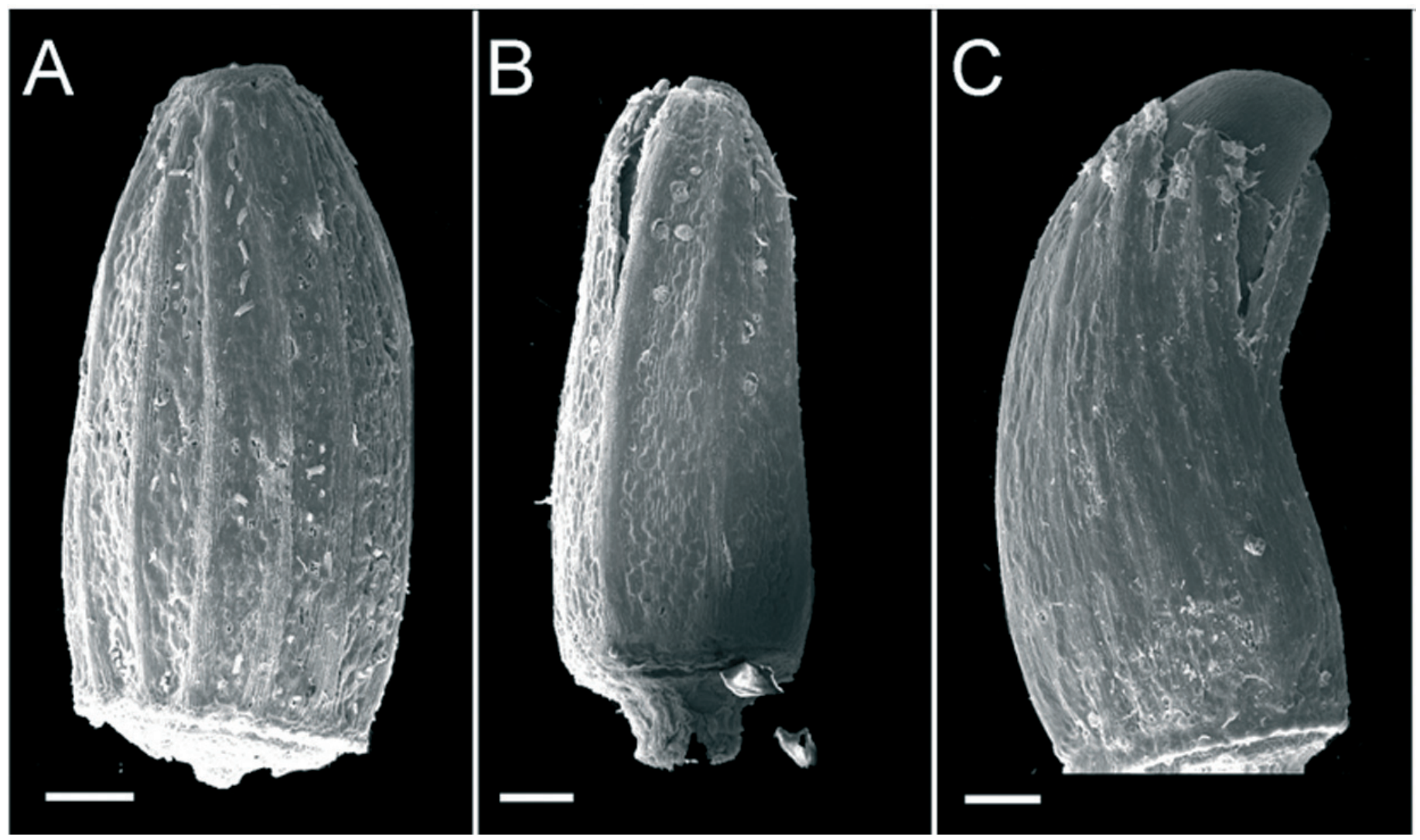

Concomitantemente, com os eventos fisiológicos e mudanças morfológicas que ocorreram na semente, houve início da degradação de reservas das sementes. Isso pode ser confirmado através da presença de atividade da enzima endo$\beta$-mananase após $12 \mathrm{~h}$ de embebição, porém com valores bastante reduzidos até $96 \mathrm{~h}$ quando foi verificado aumento da sua atividade, coincidindo com a germinação de $50 \%$ das sementes (Figuras 1 e 4). Assim, a atividade de endo- $\beta$ mananase, aumentou apenas após a emissão da raiz primária e mais que triplicou após a germinação das sementes. Estes resultados são semelhantes aos observados em sementes de alface, em que a atividade desta enzima aumenta no endosperma apenas após a o início da germinação das sementes (Bewley, 1997). Aparentemente, esta enzima está amplamente associada com mobilização de reservas presentes nas paredes celulares como uma fonte inicial de reservas na forma de carboidratos para o início do estabelecimento da plântula (Bewley e Black, 1994).
FIGURA 4. Atividade da enzima endo- $\beta$-mananase em sementes de Eremanthus erythropappus durante a embebição em água. (Médias de três repetições)

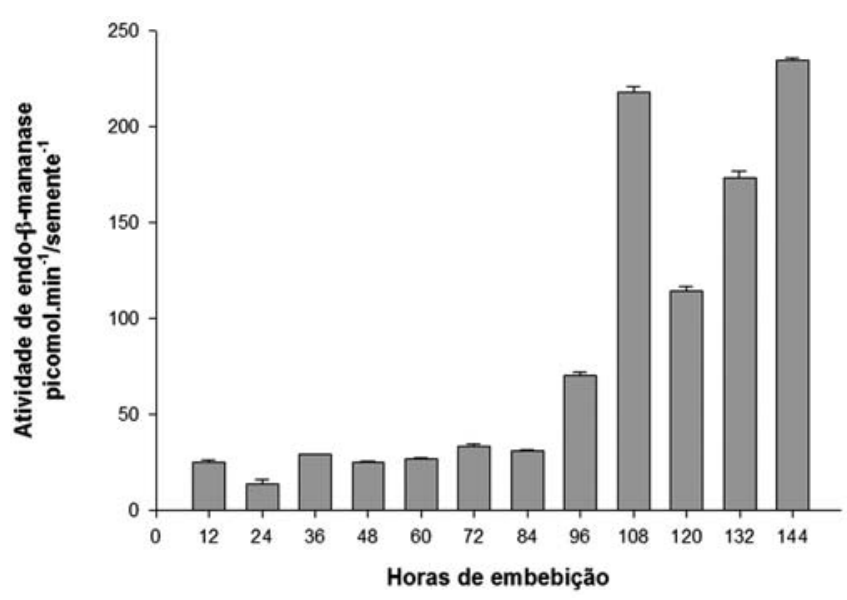




\section{CONCLUSÕES}

A condição ótima para germinação de sementes de $E$. erythropappus é temperatura alternada de $20-30^{\circ} \mathrm{C}$ com $14 \mathrm{~h}$ de fotoperíodo.

As sementes apresentam um padrão trifásico de embebição em água sendo que a fase II inicia-se em torno de 24h e a fase III (germinação) a partir de 96h de embebição.

Alterações morfológicas no tegumento, endosperma e radícula se acentuam com a emissão e crescimento da raiz primária.

O endosperma micropilar é reduzido sendo formado por duas ou três camadas de células.

A atividade da enzima endo- $\beta$-mananase aumenta após a emissão da raiz primária.

\section{REFERÊNCIAS}

ALVES, E. Apostila do curso introdutório à microscopia eletrônica de varredura. Lavras: Editora UFLA, 2004. 43p.

BEWLEY, J.D.; BLACK, M. Seeds: physiology of development and germination. New York: Plenum Press, 1994. 455p.

BEWLEY, J.D. Breaking down the walls - a role for endo- $\beta$ mannanase in release from seed dormancy? Trends in Plant Science, Oxford, v.2, n.12, p.464-469, 1997.

CETEC - Centro Tecnológico de Minas Gerais. Ecofisiologia da candeia. Belo Horizonte: SAT/CETEC, 1994. 104 p.

CHAVES, M.M.F.; RAMALHO, R.S. Estudos morfológicos em sementes, plântulas e mudas de duas espécies arbóreas pioneiras da família Asteraceae (Vanillosmopsis erythropappa Sch. Bip e Vernonia discolor (Spreng.) Less). Revista Árvore, Viçosa, v.20, n.1, p.1-7, 1996.

COPELAND, L.O.; MCDONALD, M.B. Principles of seed science and technology. London: Kluwer Academic Publishers, 1999. 409p.
DA SILVA, E.A.A; TOOROP E.P.; VAN AELST, A.C.; HILHORST, H.W.M. Abscisic acid controls embryo growth potential and endosperm cap weakening during coffee (Coffea arabica cv. Rubi) seed germination. Planta, Berlin, v.220, n.2, p.251-261, 2004.

DOWNIE, B.; HILHORST, H.W.M.; BEWLEY, J.D. A new assay for quantifying endo- $\beta$-mannanase activity using Congo Red dye. Phytochemistry, Oxford, v.36, n.4, p.829835, 1994.

NEMAF - Núcleo de Estudos em Manejo Florestal. “Sistema de manejo para a candeia (Eremanthus erythropappus e Eremanthus incanus)". Disponível em: < www. nucleoestudo.ufla.br/nemaf > . Acesso em: 01 set. 2007.

PEREZ, J.F.M. Sistema de manejo para a candeia (Eremanthus erythropappus (DC.) MacLeish). 2001. 71f. Dissertação (Mestrado em Engenharia Florestal) Universidade Federal de Lavras, Lavras.

OLIVEIRA-FILHO, A.T. Catálogo das árvores nativas de Minas Gerais. Lavras: UFLA, 2006. 423p.

PINTO, L.V.A.; DA SILVA, E.A.A.; DAVIDE, A.C.; JESUS, V.A.M.; TOOROP, P.E.; HILHORST, H.W.M. Mechanism and control of Solanum lycocarpum St. Hill seed germination. Annals of Botany, Oxford, v.100, n.6, p.11851187, 2007.

SANTOS, S.R.G.; AGUIAR, I.B. Efeito da temperatura na germinação de sementes de Sebastiania commersoniana (Baillon) Smith \& Downs separadas pela coloração do tegumento. Scientia Forestalis, Piracicaba, v. 69, p.77-83, 2005.

TONETTI, O.A.; DAVIDE, A.C.; DA SILVA, E.A.A. Qualidade física e fisiológica de sementes de candeia (Eremanthus erythropappus (DC.) Mac. Leish). Revista Brasileira de Sementes, Pelotas, v.28, n.1, p.114-121, 2006.

WANG A.; JIERAN L.; BEWLEY, J.D. Molecular cloning and characterization of an endo- $\beta$-mannanase gene expressed in the lettuce endosperm following radicle emergence. Seed Science Research, Cambridge, v.14, n.3, p.267-276, 2004. 